\title{
ESwift: Smart and Self-Stabilizing Water-Wind Floating Turbine
}

\author{
Minh N. Doan ${ }^{1, *\left(\mathbb{D}, \text { Mehdi Badri }^{1} \text {, Trung B. Tran }\right.}{ }^{2}$ and Yuriko Kai ${ }^{1,}$ \\ Department of Mechanical Engineering, Keio University \\ 2 Department of Mechanical Engineering, Bucknell University \\ * Correspondence: minh.doan@bucknell.edu
}

\begin{abstract}
In April 2019, a team of Keio University and Bucknell University students was assembled to participate in Ericsson Innovation Awards with a novel concept for generating renewable energy. This conceptual system consists of a vertical axis wind turbine, a crossflow marine hydrokinetic turbine, a floating platform integrated with a quadcopter system, and three to four temporary mooring lines with ship-type anchors. The proposed designed aims to offer solutions to two current problems of floating offshore wind energy: high construction cost of floating platforms and difficulties in maintenance of mooring lines. The combination of two vertical-axis turbines into a single floating platform would enable the system, namely ESwift, to extract energy from both wind and current resources. Additionally, due to the utilization of vertical axis turbines, the center of gravity of the proposed concept is significantly lower with respect to water level, compared to that of existing floating horizontal axis wind turbines, which would potentially reduce the floater's size and construction cost. Lastly, the integrated quadcopter mechanism would assist the floater in terms of stability and mobility, and enables an array of ESwifts to automatically rearrange for maximal energy generation. The authors hope that readers would find the idea described in this open access letter worth pursuing and would further develop and commercialize the ESwift concept.
\end{abstract}

Keywords: marine hydrokinetic turbine; wind energy; floating offshore wind turbine; mooring lines; floating platform; vertical axis turbine

\section{INTRODUCTION}

Elon Musk once said that "the future of humanity is fundamentally going to bifurcate along one of two directions: either we are going to become a multi-planet species and a space-faring civilization, or we are going be stuck on one planet until some eventual extinction event." Refusing to believe in the latter scenario, Mr. Musk works tirelessly to establish Tesla's electric automobiles, Solar City's solar roof, The Boring Company's transportation system, and SpaceX's rockets. Our four-member team also aspires to realize such hope by contributing our ideas and efforts with this project. This letter briefly describes and discusses our concept of a floating device generating energy from renewable resources that not only considerably increases power generation through innovative design and self-optimization, but also greatly reduces the installation cost and minimizes the maintenance effort compared to commercialized technologies.

\section{CONCEPT}

The proposed concept, namely ESwift, which stands for smart and self-stabilizing water-wind floating turbine, is technologically distinct from existing solutions in three innovative features. Firstly, the design consists of one vertical axis wind turbine (VAWT) and one crossflow marine hydrokinetic turbine (MHKT) arranged in a coaxial fashion, with an electric generator located near the water surface. Secondly, the floating platform, on which the system resides, is held in place by one to four ship type anchors temporarily moored to the sea bed and is incorporated with a submerged quad-propeller assistive stabilizer/mobilizer. Thirdly, the floating device is equipped with communication systems 

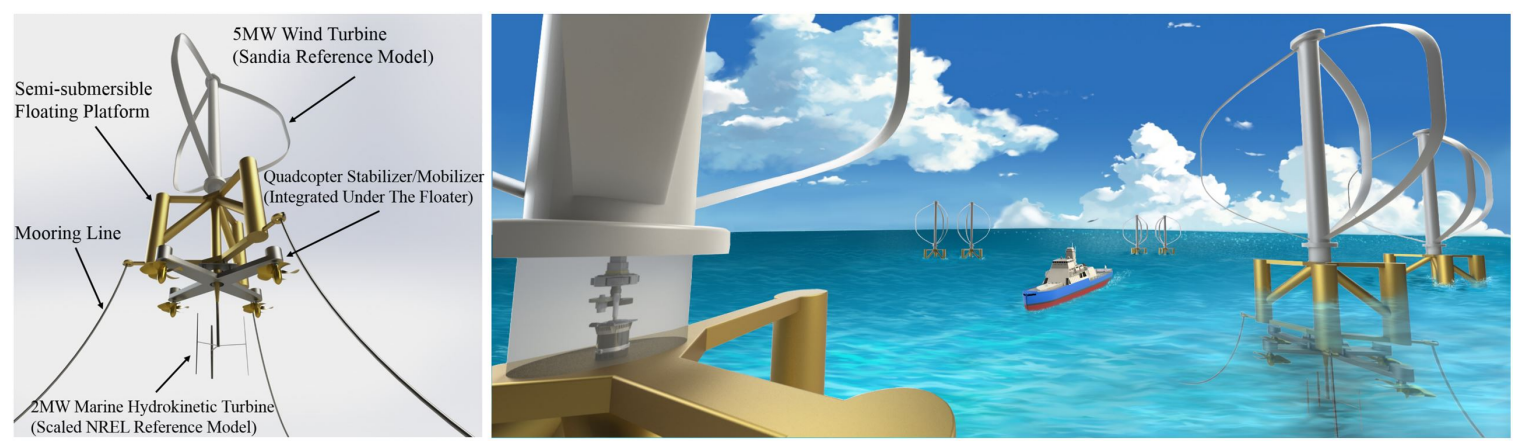

Figure 1. Concept art of the ESwift. The right displays its major components. The left picture illustrates a network of the ESwifts collaborating in counter rotating pairs for maximal power production.

that exchange information with a headquarter as well as other neighboring turbines, enabling them to synchronously rearrange under different operating conditions for optimal power production, to escape from extreme weather fluctuations, and to autonomously return to dock in case when maintenance or repair is required.

The ESwift core design includes the integration of a hydrokinetic and a wind turbine, a combination currently does not exist on the market. Because of the numerous technical challenges relating to the design and assimilation of a MHKT into an industrial archetype horizontal axis wind turbine (HAWT), much hesitations exist when pursuing this direction, particularly in terms of early stage prototyping. While the HAWT design could withstand stronger aerodynamic loads and resist more fatigue damages, the VAWT design possesses its own advantages, such as higher compactness, easier maintenance of heavy equipment, and being omni-directional to the wind. Furthermore, when operating in marine environment with much higher fluid density, a horizontal axis turbine blade encounters a huge difference in hydrodynamic loads in a revolution that would eventually lead to fatigue damages. On the other hand, a vertical axis turbine design does not face this problem as each blade section stays at the same water depth in a revolution. More importantly, multiple recent academic studies have shown that two adjacent counter-rotating vertical axis turbines could potentially increase one order of magnitude of their power output compared to horizontal axis turbines of the same size [1-4]. The fact that developments of marine hydrokinetic devices still put the vertical axis (crossflow) turbines at the forefront $[5,6]$, combined with the advantages of VAWTs over HAWTs, naturally implies the proposed design in this document. Many technical challenges would be resolved with the high compatibility of the two vertical axis turbines. Regarding the concept of the floating structure and stabilizing/mobilizing system, both mechanisms are well understood nowadays: the oil and gas industries have provided extensive knowledge on floating platforms, while the aerospace industry has much experience in the designing and commercializing quadcopter drones. Thus, the ability to design the proposed system is undeniably within reach. With the current experience on self-driving cars and fly-by-wire aircrafts, along with the rise of the Internet of things and the $5 \mathrm{G}$ network, the same claim can also be made on the proposed communication/control system. With a stability assistive quadcopter mechanism attached to the floating platform, the number of mooring lines are reduced and their associated permanent anchors are replaced with the temporary ship type anchors. Since these temporary lines can be retracted and the quad-propeller can also serve as a mobilizer, the ESwift will be able to move on its own to a designated location. Compared to existing technologies, such as floating offshore wind turbines (FOWTs) and axial-flow (horizontal axis) MHKTs, a network of the ESwifts would considerably increase the energy production, not only because of the efficient designing concept, but also due to its ability to tap into two different types of renewable energy. The quad-propeller self-stabilizing/mobilizing control, coupled with the communication electronics system, allows an array of the proposed turbines to optimize their configuration for maximal energy production (by moving the turbines into counter-rotating pairs, for instance) and to relocate to distanced wind or ocean locations to increase their power supply, depending on the season and environmental condition. 
112

Regarding the construction cost and environmental impact, the ESwift would outperform current FOWTs, due to having a lower number of mooring lines. Current platform design for a FOWT usually requires three to eight custom made mooring lines to be permanently anchored into the sea bed. Although this mooring design seems to be economical and technologically practical for keeping the FOWT sturdily afloat, in the long run, it will create environmental and financial problems, as the mooring lines and their permanent joints need to be regularly maintained and must be replaced or disposed after the turbine lifetime. The proposed assistive stabilizing system uses only up to four retrievable ship anchors, which are relatively inexpensive and commonly used in the maritime industry. While this configuration is generally not robust enough for a FOWT, its combination with a quad-propeller system ensures perfect safety and stability for different operating conditions, ranging from high wave to rough wind. In terms of maintenance, the turbine concept would significantly decrease costs and hazards compare to current FOWTs and axial-flow MHKTs. For existing design, the maintenance of the electric generator of a horizontal axis turbine typically takes place at about 100 meters above the sea level (for FOWTs) or 40 meters under the sea level (for MHKTs). Similarly, the maintenance of the mooring lines that connect the floating platform to the sea bed at a depth of hundreds of meters needs extremely strenuous efforts, which require equivalently high-skilled personnel. Not only has the ESwift placed its electric generator at the base of the floating platform, but it also includes only temporary anchors that can be retracted and a quad-propeller system that can relocate itself to a designated maintaining location close to shore. These make the maintenance work of FOWTs accessible via regular ships, eliminate the needs to operate in unsafe working conditions, and transform the maintaining task into a more centralized and industrialized activity.

\section{CONCLUSION}

To sum up, the team hopes to improve existing FOWT and MHKT technology with the three innovative features of the proposed system. An Internet of the ESwift devices would outperform that of the current technologies in terms of energy production, construction costs, environmental friendliness, and maintenance safety and expenditures. Potential customers are governments that want to shift their energy supply from fossil or nuclear to renewable, energy firms that hope to diversify and increase their energy production, and floating platform manufacturers who desire to replace their currently permanent mooring lines with the described smart quad-propeller stabilizer/mobilizer system.

Funding: This project was partly funded by the Keio Leading-edge Laboratory of Science and Technology grant. Acknowledgments: The team thanks Prof. Shinnosuke Obi and Prof. Koji Fukagata for their support during the 2019 Ericsson Innovation Awards semi-final.

Conflicts of Interest: The authors declare no conflict of interest.

\section{Abbreviations}

The following abbreviations are used in this manuscript:

MDPI Multidisciplinary Digital Publishing Institute

MHKT Marine Hydrokinetic Turbine

FOWT Floating Offshore Wind Turbine

HAWT Horizontal Axis Wind Turbine

VAWT Vertical Axis Wind Turbine

ESwift Smart and Self-Stabilizing Water-Wind Floating Turbine

\section{References}

1. Dabiri, J. Potential order-of-magnitude enhancement of wind farm power density via counter-rotating vertical-axis wind turbine arrays. Journal of Renewable and Sustainable Energy 2011, 3. 
2. Doan, M.N.; Alayeto, I.H.; Padricelli, C.; Obi, S.; Totsuka, Y. Experimental and Computational Fluid Dynamic Analysis of Laboratory-Scaled Counter-Rotating Cross-Flow Turbines in Marine Environment. ASME 2018 5th Joint US-European Fluids Engineering Division Summer Meeting; American Society of Mechanical Engineer, , 2018; Vol. 2, p. V002T14A003. 83030.

3. Li, Y.; Calisal, S. Modeling of twin-turbine systems with vertical axis tidal current turbines: Part I-Power output. Ocean Engineering 2010, 37, 627-637.

4. Li, Y.; Calisal, S. Modeling of twin-turbine systems with vertical axis tidal current turbine: Part II-torque fluctuation. Ocean Engineering 2011, 38, 550-558.

5. Bachant, P.; Wosnik, M. Modeling the near-wake of a vertical-axis cross-flow turbine with 2-D and 3-D RANS. Journal of Renewable and Sustainable Energy 2016, 8, 053311.

6. Strom, B.; Johnson, N.; Polagye, B. Impact of blade mounting structures on cross-flow turbine performance. Journal of Renewable and Sustainable Energy 2018, 10. 